\title{
Prophylactic technique for preventing inward stent migration during placement of multiple plastic stents in a patient with surgically altered anatomy
}

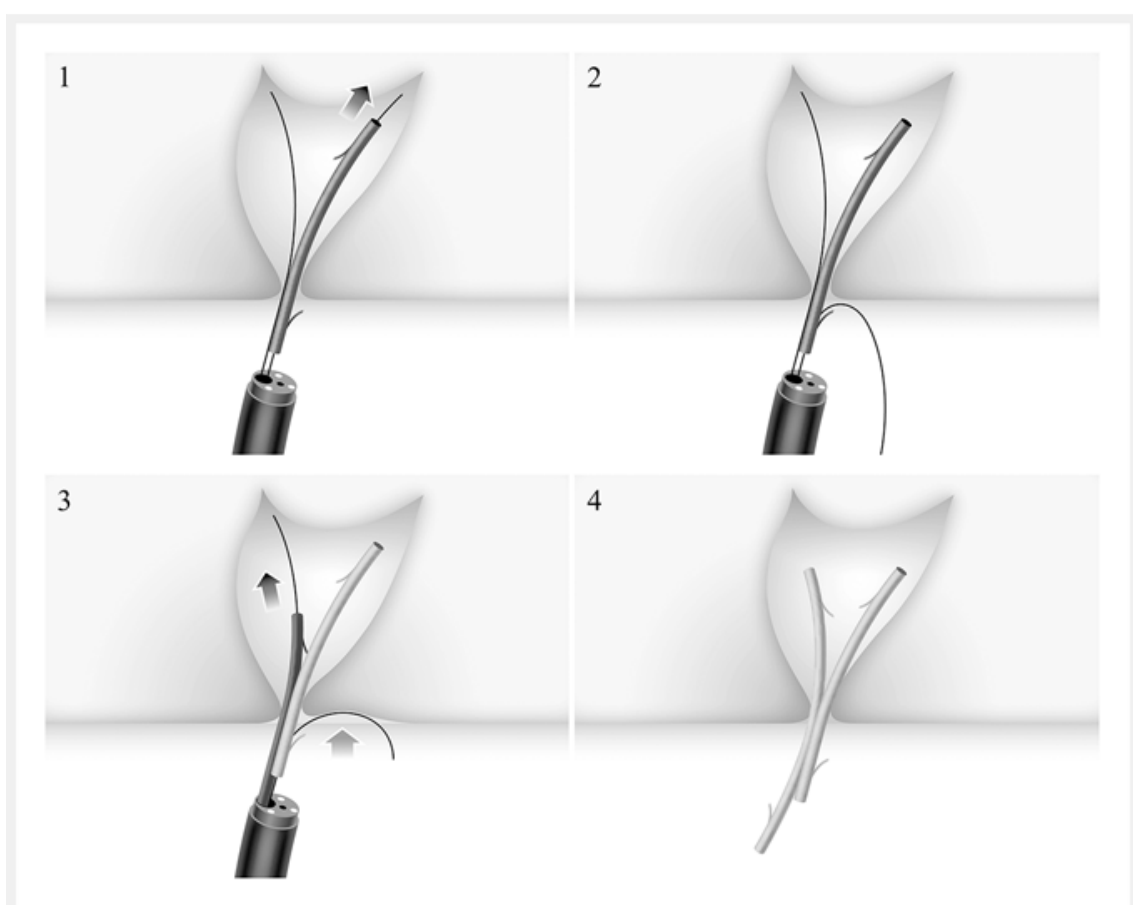

- Fig. 1 Conceptual diagram of the prophylactic technique to place multiple plastic stents in a patient with a surgically altered anatomy. Source: Nagoya City University Graduate School of Medical Sciences.
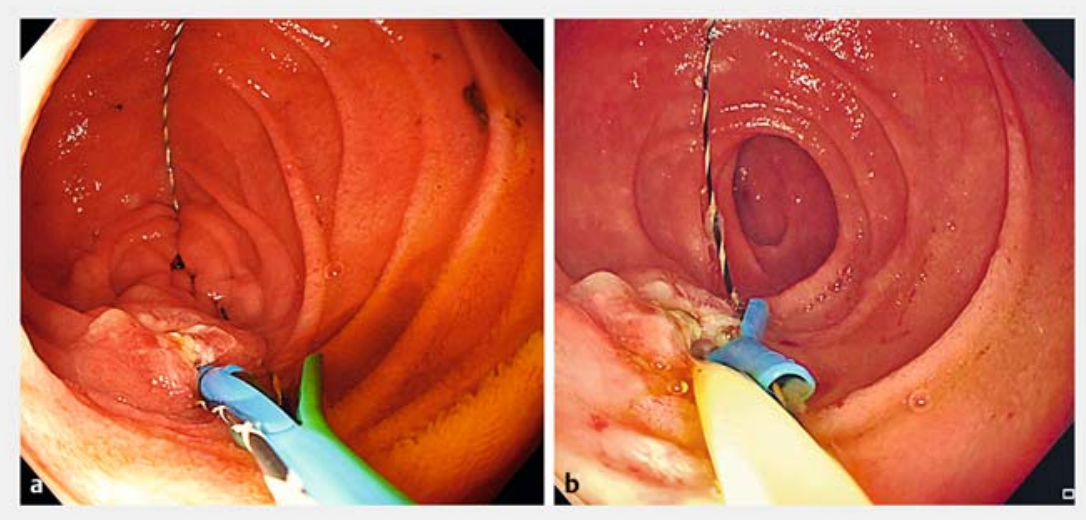

- Fig. 3 Endoscopic view showing: a the guidewire that was passed though the side-hole of the first plastic stent, thereby preventing its migration during insertion of the second biliary stent; $\mathbf{b}$ the first guidewire that came from the side-hole of the first biliary stent became stuck in place and prevented inward migration while the second biliary stent was being inserted.

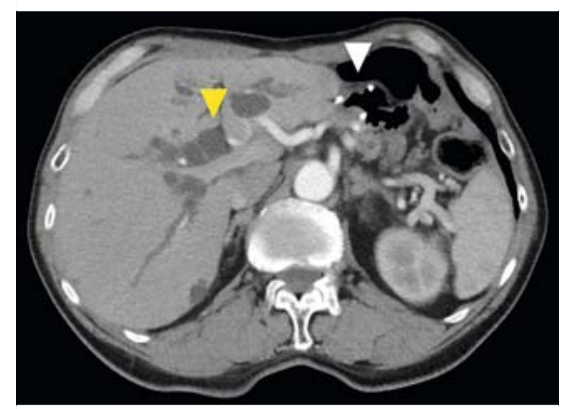

- Fig. 2 Computed tomography scan in a 77-year-old man with a Roux-en-Y reconstruction following a gastric cancer operation (white triangle) showing evidence of obstructive jaundice (yellow triangle).

Endoscopic biliary stenting is a widely accepted method to treat benign and malignant biliary strictures [1,2]. Multiple plastic stents are recommended for treating benign biliary strictures [3,4]. However, there is a risk of inward migration of a previously placed stent during insertion of the subsequent stent owing to interference of the stent in the biliary stricture. In the case of surgically altered anatomy in particular, few suitable devices are available to remove a migrated stent from an inward bile duct, and it is difficult to recover the situation [5]. Therefore, it is necessary to prevent inward stent migration when placing multiple stents. Here, we report a prophylactic technique to place multiple plastic stents safely and reliably in a patient with a surgically altered anatomy ( $\triangleright$ Fig. 1).

A 77-year-old man with a Roux-en-Y reconstruction was diagnosed with obstructive jaundice (> Fig.2). He was scheduled to undergo endoscopic biliary stenting using an enteroscope. After the ampulla of Vater had been reached, we inserted two guidewires across the stricture and placed the first straight-type plastic stent, leaving the guidewire in 


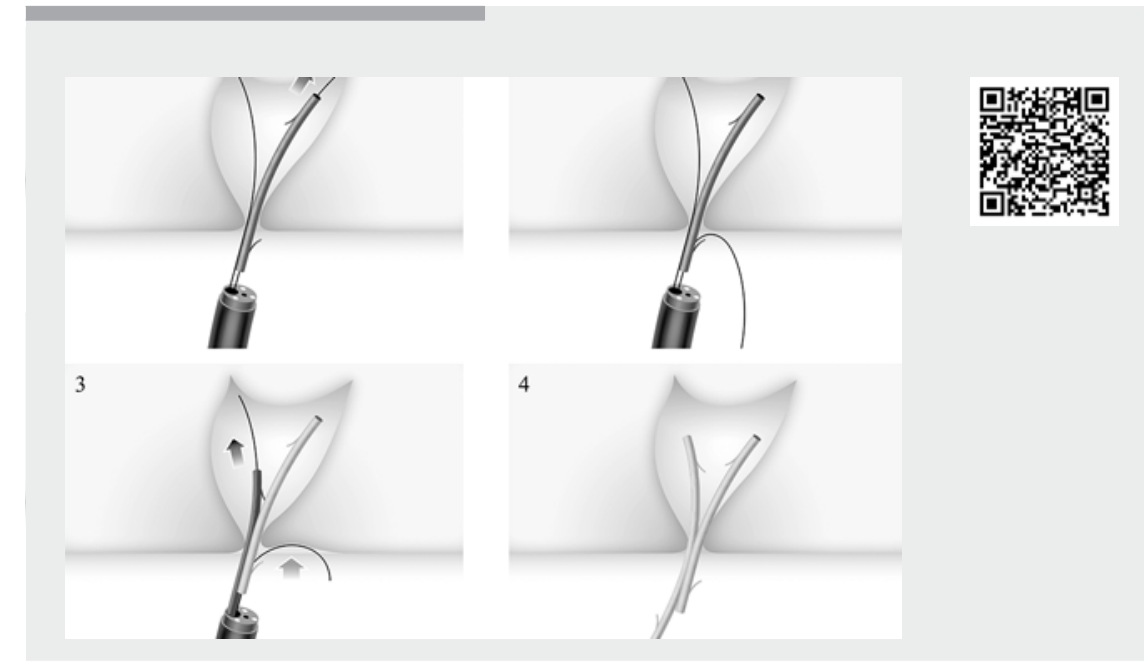

Video 1 Prophylactic technique for preventing inward stent migration during placement of multiple plastic stents in a patient with a surgically altered anatomy. Source for video image: Nagoya City University Graduate School of Medical Sciences. place without pulling it out through the stent. Subsequently, to prevent inward migration of this first stent, we pulled the guidewire back and looked for the side-hole of the stent. The guidewire was then passed through the side-hole of the first plastic stent, which subsequently prevented its inward migration during insertion of the second stent ( $\vee$ Fig. $\mathbf{3 a}$ ). The first guidewire, now coming from the side-hole of the first stent, became stuck in place during insertion of the second biliary stent, thereby acting as an antimigration system ( $\bullet \mathbf{F i g . 3} \mathbf{b}$; - Video 1). The patient's obstructive jaundice resolved after placement of the biliary stents.

This technique is a useful option to prevent inward migration of a plastic stent during placement of multiple plastic stents in a patient with a surgically altered anatomy.

Endoscopy_UCTN_Code_TTT_1AR_2AZ

\section{Competing interests}

The authors declare that they have no conflict of interest.

The authors

Kenta Kachi, Yasuki Hori, Kazuki Hayashi, Itaru Naitoh, Michihiro Yoshida, Hiromi

\section{Kataoka}

Department of Gastroenterology and Metabolism, Nagoya City University Graduate School of Medical Sciences, Nagoya, Japan

\section{Corresponding author}

\section{Yasuki Hori, MD, PhD}

Department of Gastroenterology and Metabolism, Nagoya City University Graduate School of Medical Sciences, 1 Kawasumi, Mizuho-cho, Mizuho-ku Nagoya 467-8601, Japan

Fax: +81-52-8520952

yhori@med.nagoya-cu.ac.jp
[1] Hori Y, Hayashi K, Yoshida M et al. New concept of traction force applied to biliary selfexpandable metallic stents. Endoscopy 2016; 48: 472-476

[2] Hori Y, Hayashi K, Yoshida M et al. Novel characteristics of traction force in biliary self-expandable metallic stents. Dig Endosc 2017; 29: 347-352

[3] Draganov P, Hoffman B, Marsh W et al. Longterm outcome in patients with benign biliary strictures treated endoscopically with multiple stents. Gastrointest Endosc 2002; 55: $680-686$

[4] Costamagna G, Pandolfi M, Mutignani M et al. Long-term results of endoscopic management of postoperative bile duct strictures with increasing numbers of stents. Gastrointest Endosc 2001; 54: 162 - 168

[5] Hori Y, Naitoh I, Miyabe K et al. Simultaneous side-by-side bilateral metal stent placement using a colonoscope in a patient with Billroth II reconstruction. Endoscopy 2018; 50: E218-E219

\section{Bibliography}

DOI https://doi.org/10.1055/a-1012-1709

Published online: 27.9.2019

Endoscopy 2019; 51: 234-235

(c) Georg Thieme Verlag KG

Stuttgart · New York

ISSN 0013-726X

\section{ENDOSCOPY E-VIDEOS}

https:/|eref.thieme.de/e-videos

Endoscopy E-Videos is a free access online section, reporting 自锥: on interesting cases and new techniques in gastroenterological endoscopy. All papers include a high quality video and all contributions are freely accessible online.

This section has its own submission website at https://mc.manuscriptcentral.com/e-videos 